Jurnal Ilmiah Mahasiswa Kendali dan Listrik
Vol. 1, No. 1, June 2020,1 -6

\title{
SISTEM PENGAMAN PINTU OTOMATIS DENGAN MIKROKONTROLER ARDUINO DAN MODULE RF REMOTE
}

\author{
Achmad Irvandi Yusuf ${ }^{1}$, S. Samsugi ${ }^{2}$, Fika Trisnawati $^{3}$ \\ ${ }^{1}$ Program Studi D3 Teknik Komputer Fakultas Teknik Dan Ilmu Komputer Universitas Teknokrat Indonesia \\ ${ }^{2,3}$ Program Studi S1 Teknik Elektro Fakultas Teknik Dan Ilmu Komputer Universitas Teknokrat Indonesia \\ achirvandiyusuf@gmail.com,s.samsugi@teknokrat.ac.id, fikat18@gmail.com
}

\begin{abstract}
This final task report aims to design and Meng-implementasikan a series that serves to security and follow technology installed on the security of the door and controlling the existing doors of the door such as the Module key of the RF Remote Arduino that is for opening and closing doors. And discussing about RF Remote which is used to detect a frequency that will be output and input for the Arduino microcontroller. To control the Arduino microcontroller used the C and Arduino programming languages by using the Arduino software. The way this tool works is when people want to be quick and concise in opening and closing its doors. The door that has been on the security of the RF Remote will not be in the process, if the RF Remote button does not press on the password that has been known on the microcontroller, if the existing door lock RF Remot will turn on the opening and closing doors. In the door there is also a sound mark when in the Sensor Switch does not get a hard enough clearance or emphasis, if the microcontroller does not GET the ID for 5 seconds and automatically instantly Sounds The buzzer or sound of the alarm tone if the door is forced to open or close. The RF Remote Module receives a frequency signal and is connected to the Solenoid door lock, and is processed by the Arduino and then to through the relay to connect the line current on the door lock Solenoid and Servo Motor.

Kata Kunci: Pengaman pintu, Otomatis, Arduino, Modul RF Remote
\end{abstract}

\begin{abstract}
Abstrak
Laporan tugas akhir ini bertujuan merancang dan meng-implementasikan sebuah rangkaian yang berfungsi untuk keamanan dan mengikuti teknologi yang dipasang pada keamanan pintu dan mengendalikan yang ada pada pintu seperti kunci Module RF Remote berbasis Arduino yang untuk membuka dan menutup pintu. Dan membahas mengenai RF Remote yang digunakan untuk mendeteksi sebuah frekuensi yang akan menjadi output dan input bagi mikrokontroler Arduino. Untuk mengontrol mikrokontroler Arduino digunakan bahasa pemrograman C dan Arduino dengan menggunakan sofware Arduino. Cara kerja alat ini adalah apabila orang ingin cepat dan ringkas dalam membuka dan menutup pintu nya. Pintu yang sudah di beri keamanan RF Remote tidak akan berfugsi, apa bila di tombol RF Remote tidak di tekan sandi tersebut yang telah dikenal pada mikrokontroler, bila kunci pintu yang sudah ada RF Remot akan menghidupkan proses membuka dan menutup pintunya. Di pintu juga ada tanda bunyi ketika di Sensor Switch tidak mendapatkan pengijinan atau penekanan yang cukup keras, jika mikrokontroler tidak mendapatkan ID selama 5 detik dan secara otomatis langsung membunyikan Buzzer atau suara nada alarm jika pintu dipaksa dibuka atau ditutup. Module RF Remote menerima sinyal frekuensi dan dinputkan pada Solenoid door lock, dan diolah oleh Arduino lalu di outputkan melalui relay untuk menghubungkan arus jalur pada Solenoid door lock dan Motor Servo.

Kata Kunci: Pengaman pintu, Otomatis, Arduino, Modul RF Remote
\end{abstract}

To cite this article:

Authors. (2020). Title of the article. Jurnal Ilmiah Mahasiswa Kendali dan Listrik, Vol: 1, No: 1, Hal. 1 - 6. 


\section{PENDAHULUAN}

Tindakan pencurian terjadi saat penghuni rumah sedang berpergian atau tingkat kesibukan masyarakat akan pekerjaan yang menyebabkan kurangnya perhatian terhadap keamanan rumah dari bahaya tindakan kriminal pencurian. Sehingga ada perasaan khawatir atau was-was saat akan meninggalkan rumah atau perkantoran baik dalam waktu yang lama maupun waktu yang relatif sebentar. Untuk mengatasi hal itu diperlukan suatu penjagaan atau menyewa security atau private guard untuk menjaga keamanan kompleks perumahan, rumah indekos atau pun perkantoran. Dengan langkah ini harus ditebus dengan harga yang mahal, dan kurang efektif karena kemampuan security sangat terbatas dan biaya yang mahal untuk membayarnya.

Dengan kemajuan teknologi saat ini masalah tersebut bisa diatasi dengan "Sistem Keamanan Rumah Menggunakan MODUL RF REMOTE Berbasis ARDUINO" yaitu sistem keamanan menggunakan MODUL RF REMOTE Adalah alat yang bisa digunakan sebagai pengaman biasanya terpasang pada jendela, pintu dan akses keluar masuk seseorang ke dalam ruangan tertentu, sehingga apabila ada pembobolan dan cara masuk yang memaksa maka alarm akan berbunyi dengan sangat keras sehingga akan mencegah tindakan kejahatan yang dilakukan oleh orang lain, dan alat tersebut akan merespon kepada pemilik rumah melalui smartphone android yang mana memanfaatkan aplikasi ini untuk menerima responan dari pendeteksi suara yang terpasang di rumah serta menangkap gambar rekaman orang yang mencoba masuk rumah. Diharapkan dengan sistem keamanan pintu ini bisa mengurangi resiko akan tindakan kejahatan pencurian pada saat pemilik rumah berpergian dalam jangka waktu yang lama.

\section{TELAAH PUSTAKA}

Mikrokontroller adalah suatu rangkaian elektronik yang berfungsi sebagai pengendali yang mengatur jalannya proses kerja dari rangkaian elektronik. Di dalam sebuah IC mikrokontroller terdapat CPU, Memori, Timer, Input/Output, Analog Digital Conveter (ADC), Digital Analog Conveter dan lain-lain [1]. Beberapa fitur yang umumnya ada didalam microcontroller seperti, RAM, ROM, Register, SFR,Interrupt, External Interrupt, Interupt serial.

Pemrograman microcontroller dapat dilakukan dengan software IDE (Integrated Development Environment) yang merupakan suatu kumpulan urutan perintah ke komputer dengan menggunakan bahasa yang mudah dimengerti sehingga komputer dapat mengerjakan sesuai dengan perintah.man merupakan suatu kumpulan urutan perintah ke komputer untuk mengerjakan sesuatu. Perintah - perintah ini membutuhkan suatu bahasa sendiri yang dapat dimengerti oleh komputer [2]. Pemrograman ini memiliki dua buah software IDE yang sering digunakan oleh para programmer yaitu code vision AVR dan Arduino IDE, pengoperasian software IDE ini menggunakan bahasa $\mathrm{C}$ atau ansambler yang merupakan bahasa yang digunakan dalam pemrograman microcontroller. Arduino merupakan rangkaian elektronik yang bersifat open source, serta memiliki perangkat keras dan lunak yang mudah untuk digunakan. Arduino dapat mengenali lingkungan sekitarnya melalui berbagai jenis sensor dan dapat mengendalikan lampu, motor, dan berbagai jenis aktuator lainnya. Arduino mempunyai banyak jenis, di antaranya Arduino Uno, Arduino Mega 2560, Arduino Fio, dan lainnya [3].

Pemrograman arduino menggunakan bahasa $\mathrm{C}$ yang telah disederhanakan dan sangat mudah untuk dipahami. Bahasa C tersebut memiliki struktur (void setup dan void loop), variable, syntax, operator matematika, operator pembanding dan struktur operator. Komponen yang digunakan selain Arduino adalah LCD 16x2, buzzer, motor servo, relay, RF Module Remote, solenoid door, modul relay 4 channel, dan komponen elektronika (led, resistor, kapasitor, diode, resistor variable, dan transformator). Penelitian sejenis yaitu Buka tutup atap otomatis merupakan bagian dari rumah yang berfungsi untuk membuka dan menutup secara otomatis dengan pendeteksi hujan berbasis Arduino [5]. pada penelitian berikutnya dibangun sebuah alat pengaman pintu ini memanfaatkan E-KTP untuk membuka pintu. RFID reader 13,56 MHz digunakan untuk membaca nomor ID pada E-KTP, mikrokontroler ATmega328 sebagai pengatur input/output rangkaian [6]. Penelitian yang terkait berikutnya adalah Sistem Pintu Otomatis dengan Barcode pada penelitian ini adalah mikrokontroler AT89S51 sebagai sistem kontrol yang dapat merespon semua input yang didapat dari barcode reader dan mengolahnya sesuai dengan instruksiinstruksi program yang dibuat [7]. 


\section{PERANCANGAN SISTEM}

\section{Perancangan Alat}

Perancangan Alat adalah suatu metode awal dalam pembuatan sebuah alat yang sangat penting karena tanpa sebuah perancangan alat yang dibuat tidak dapat berjalan dengan maksimal. Untuk memperoleh hasil yang maksimal diperlukan rancangan yang baik dengan memperhatikan sifat dan karakteristik dari tiap-tiap komponen yang digunakan. Pada gambar di bawah ini adalah gambar diagram blok dari mikrokontroller alat ini.

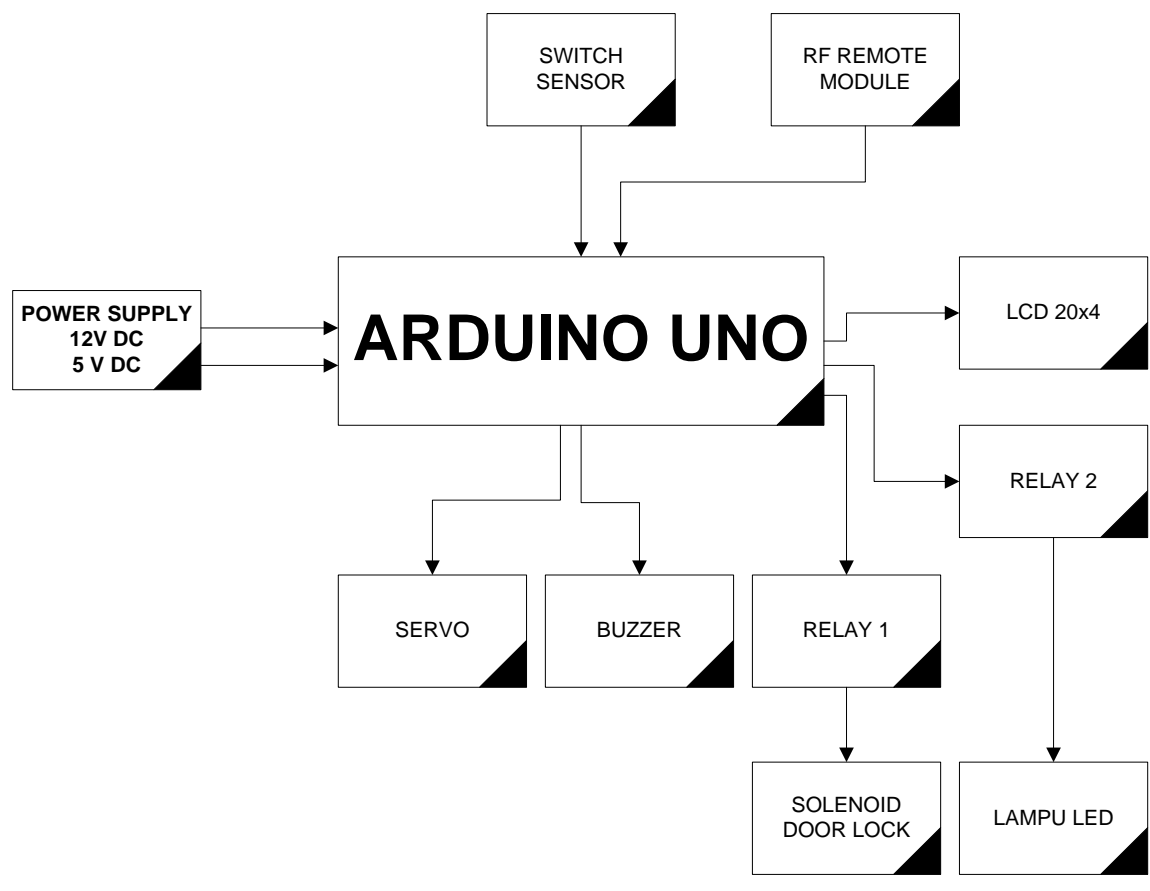

Gambar 1 Diagram Blok Kerja Alat

Perancangan rangkaian keseluruhan alat terdiri dari empat elemen penting yang saling terintegrasi. Elemenelemen penting tersebut yaitu rangkaian input, rangkaian pengendali, rangkaian output dan juga software program yang saling terintegrasikan. Rangkaian yang terdiri dari komponen-komponen elektronika baik berupa input atau output yang dibutuhkan oleh mikrokontroller agar dapat berfungsi dengan baik. Rangkaian keseluruhan alat dapat dilihat pada gambar berikut: 


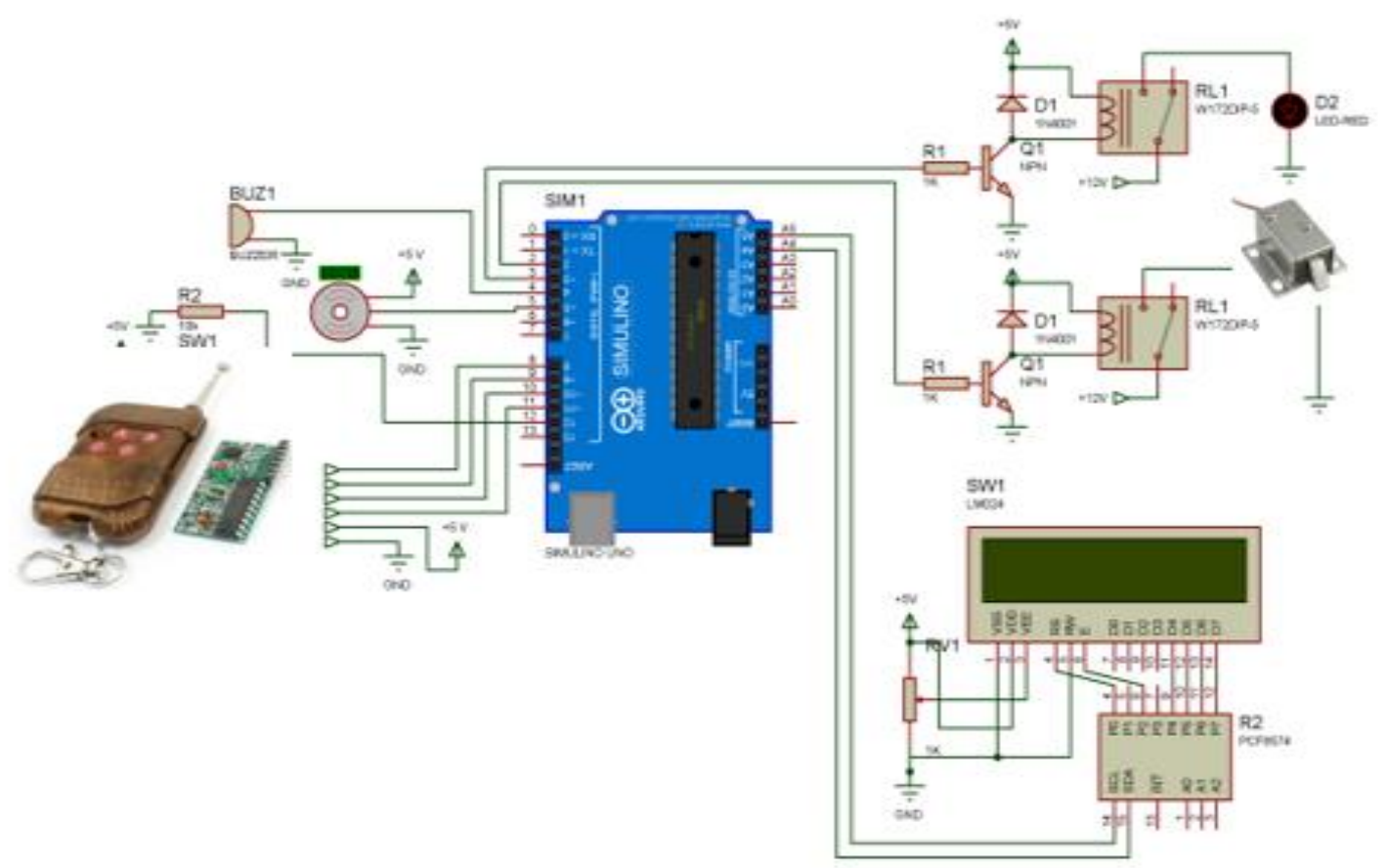

Gambar 2 Perancangan Keseluruhan Alat

\section{Alat Dan Bahan}

Dalam pembuatan alat tugas akhir ini memerlukan beberapa komponen dan bahan. Komponen dan bahan yang digunakan dalam pembuatan alat ini adalah laptop, Multitester, Bor, Solder, Penyedot Timah, Gerinder, Tang Rivet, Obeng dan Tang

Bahan-bahan yang dibutuhkan dalam pembuatan alat.

Tabel 1 Komponen Yang Digunakan

\begin{tabular}{|c|c|c|}
\hline No & Nama Komponen & Jumlah \\
\hline 1 & Arduino UNO 3 & 1 \\
\hline 2 & Switch Sensor & 1 \\
\hline 3 & Servo & 1 \\
\hline 4 & Led & 1 \\
\hline 5 & Lcd 20x4 & 1 \\
\hline 6 & Solenoid Door Lock & 1 \\
\hline 8 & IC LM7809 & Secukupnya \\
\hline 9 & IC LM7805 & Secukupnya \\
\hline 10 & Pin Header L & Secukupnya \\
\hline 11 & Elco 1000uf 25v & Secukupnya \\
\hline 12 & Elco 10uf 16v & Secukupnya \\
\hline 13 & Cramic 103 & Secukupnya \\
\hline 14 & Cramic 104 & Secukupnya \\
\hline 15 & Elco 1000uf 32v & Secukupnya \\
\hline 16 & Elco 100uf 16v & 1 \\
\hline 17 & Resistor & Secukupnya \\
\hline 18 & Trafo CT 2 Ampere & 1 \\
\hline 19 & Kabel Pelangi & \\
\hline 20 & Kabel AC & \\
\hline
\end{tabular}


Jurnal Ilmiah Mahasiswa Kendali dan Listrik (JIMEL), Vol: 1, No: 1, Hal. 1 - 6

\begin{tabular}{|c|c|c|}
\hline 21 & Triplek & Secukupnya \\
\hline 22 & Relay 4 Chaneel & 1 \\
\hline 23 & Buzzer & 1 \\
\hline
\end{tabular}

\section{HASIL DAN PEMBAHASAN}

Tujuan pengujian mikrokontroller pada alat ini yaitu untuk menentukan kesesuaiaan alat berfungsi sesuai dengan perencanaan atau tidak dengan melakukan Pengujian pada alat ini meiputi pengujian setiap blok maupun pengujian secara keseluruhan. Pengujian setiap blok ini dilakukan untuk menentukan letak kesalahan dan mempermudah dalam analisa mikrokontroller bila alat tidak bekerja sesuai rancangan. Pengujian yang dilakukan dalam penelitian ini sebagai berikut, pengujian Power Supply, pengujian Sensor Switch, pengujian Lcd 20x4 Karakter, pengujian Servo, pengujian RF Remote Module, pengujian Buzzer, pengujian Relay.

\section{Power Supply}

Power Supply merupakan suatu komponen paling penting dalam pembuatan alat ini karena power supply adalah sumber tegangan untuk menghidupkan semua komponen yang ada. Power supply yang digunakan sebesar 2 Ampere dengan menggunakan Trafo CT yang diturukan menjadi dua buah tegangan yaitu $12 \mathrm{~V}$ de dan $5 \mathrm{~V}$ dc. Power Supply sangat penting untuk menyuplai tegangan ke sistem mikrokontroler, power supply pada alat ini menggunakan battery 9 Volt [8].

Table 2. Hasil Penggunaan Sumber Tegangan

\begin{tabular}{c|c|c|l|c}
\hline \multirow{2}{*}{ Input } & $\begin{array}{c}\text { Penurun } \\
\text { Tegangan }\end{array}$ & IC Regulator & Keterangan Kegunaan & Tegangan \\
\hline \multirow{3}{*}{$\begin{array}{c}\text { PLN 220V } \\
\text { AC }\end{array}$} & \multirow{2}{*}{$\begin{array}{c}\text { Adaptor Trafo } \\
\text { 12V DC }\end{array}$} & LM7805 & $\begin{array}{l}\text { Power Lcd } \\
\text { Power Switch Sensor } \\
\text { Power Servor } \\
\text { Power Relay }\end{array}$ & 5 Volt DC \\
\cline { 3 - 5 } & & LM7809 & Power Arduino & 9 Volt DC \\
\cline { 3 - 5 } & & - & $\begin{array}{l}\text { Power LED 12V } \\
\text { Power Solenoid Valve }\end{array}$ & 12 Volt DC \\
\hline
\end{tabular}

\section{Penggunaan Sensor Switch}

Penggunaan switch sensor pada alat ini berguna sebagai pendeteksi pergerakan kunci yang di tujukan pada pergerakan pintu apakah posisi pintu terbuka atau tertutup.

Table 3. Hasil Pengujian Sensor Switch

\begin{tabular}{c|c|c|c|c}
\hline No & Sensor IR & Kondisi & Status & Keterangan \\
\hline 1 & Sensor 1 & Low & Tertutup & Pintu Tertutup \\
\hline 2 & Sensor 1 & High & Tebuka & Pintu Terbuka \\
\hline
\end{tabular}

\section{Pengujian LCD}

Pada tahap ini adalah pengujian komunikasi mikrokontroler arduino dengan modul LCD 20x4, pada alat ini modul lcd 20x4 digunakan sebagai monitor untuk mengetahui kondisi kerja sistem pemantauan lebih mudah [4]. 


\section{Pengujian Servo}

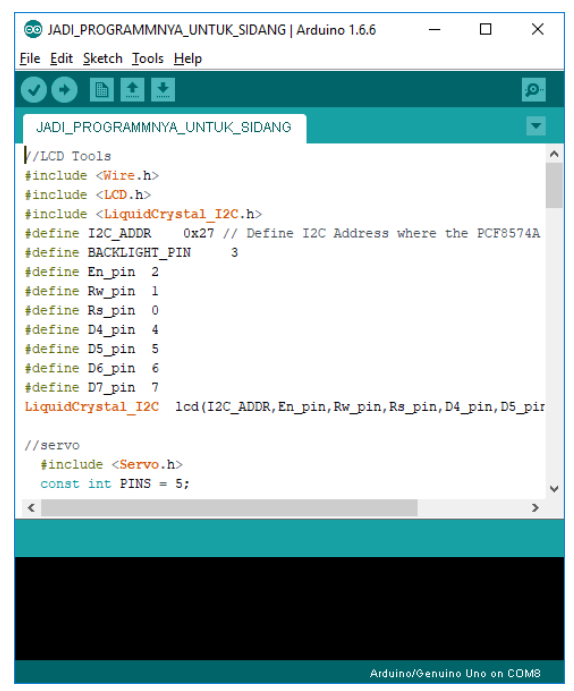

Gambar 3. Hasil Pengujian LCD

Penggunaan motor dengan gear box atau yang biasa disebut dengan servo pada alat ini digunakan sebagai penutup dan pembuka pintu.

Tabel 4. Hasil Pengujian Servo

\begin{tabular}{c|l|l|c}
\hline No & \multicolumn{1}{|c|}{ SERVO } & \multicolumn{1}{|c}{ PINTU } & Keterangan \\
\hline 1 & Posisi $133^{0}$ & Membuka & Pintu akan terbuka \\
\hline 2 & Posisi $0^{0}$ & Menutup & Pintu akan tertutup \\
\hline
\end{tabular}

\section{Pengujian RF Remote}

Penggunaan RF Remote module atau yang biasa dikenal dengan remote control wireless digunakan untuk mengontrol sistem dengan remote sehingga pengontrolan alat bisa dilakuakan tanpa menggunakan medi kabel melainkan hanya menggunakan sebuah remote untuk mengontrol sistem.

Tabel 5. Table Pengujian Sensor Ultrasonic1

\begin{tabular}{c|l|l|l|l}
\hline No & \multicolumn{1}{|c|}{ Button } & \multicolumn{1}{|c}{ Kondisi Sistem } & \multicolumn{1}{|c}{ Aksi Sistem } & \multicolumn{1}{c}{ Keterangan } \\
\hline 1 & Button A/1 & Reset /Terkunci & $\begin{array}{l}\text { Relay 2 ON Solenoid Door } \\
\text { Open }\end{array}$ & $\begin{array}{l}\text { Kunci Terbuka Dan Pintu Bisa Untuk } \\
\text { Dibuka }\end{array}$ \\
\hline 2 & Button B/2 & Kunci Terbuka & $\begin{array}{l}\text { Relay 2 OFF } \\
\text { Solenoid Door Close }\end{array}$ & Digunakan Untuk Mengunci Pintu \\
\hline 3 & Button C/3 & Kunci Terbuka & $\begin{array}{l}\text { Servo 0 Derajat } \\
\text { Relay 1 ON }\end{array}$ & $\begin{array}{l}\text { Mengerakan dan membuka pintu dan } \\
\text { menghidupkan lampu led }\end{array}$ \\
\hline 4 & Button D/4 & Kunci Terbuka & $\begin{array}{l}\text { Servo 133 Derajat Relay 1 } \\
\text { OFF }\end{array}$ & $\begin{array}{l}\text { Menggerakan Pintu dan mematikan } \\
\text { lampu dan mereset sistem untuk } \\
\text { menghidupkan alarm sehingga sistem } \\
\text { terkunci }\end{array}$ \\
\hline
\end{tabular}

\section{Pengujian Relay}

Pada perancangan alat ini penggunaan relay ditujukan untuk mengontrol solenoid door lock yang berfungsi sebagai kunci elektrik sehingga kunci bisa dikontrol otomatis oleh sistem dan pengontrol saklar lampu pada alat.

Tabel 6. Hasil Pengujian Relay

\begin{tabular}{c|l|l|l}
\hline No & RF Remote & \multicolumn{1}{c}{ Relay Status } & \multicolumn{1}{c}{ Keterangan } \\
\hline 1 & Button A/1 & $\begin{array}{l}\text { Relay 1 = OFF } \\
\text { Relay 2 }=\text { ON }\end{array}$ & $\begin{array}{l}\text { Solenoid/Kunci Terbuka } \\
\text { Lampu Off }\end{array}$ \\
\hline
\end{tabular}


Jurnal Ilmiah Mahasiswa Kendali dan Listrik (JIMEL), Vol: 1, No: 1, Hal. 1 - 6

\begin{tabular}{|c|c|c|c|}
\hline No & RF Remote & Relay Status & Keterangan \\
\hline 2 & Button $\mathrm{B} / 2$ & $\begin{array}{l}\text { Relay } 1=\text { OFF } \\
\text { Relay } 2=\text { OFF }\end{array}$ & $\begin{array}{l}\text { Solenoid/Kunci Tertutup } \\
\text { Lampu Off }\end{array}$ \\
\hline 3 & Button $\mathrm{C} / 3$ & $\begin{array}{l}\text { Relay } 1=\mathrm{ON} \\
\text { Relay } 2=\mathrm{ON}\end{array}$ & $\begin{array}{l}\text { Solenoid/Kunci Tertbuka } \\
\text { Lampu On }\end{array}$ \\
\hline 4 & Button D/4 & $\begin{array}{l}\text { Relay } 1=\text { OFF } \\
\text { Relay } 2=\text { OFF }\end{array}$ & $\begin{array}{l}\text { Solenoid/Kunci Tertutup } \\
\text { Lampu Off }\end{array}$ \\
\hline
\end{tabular}

\section{SIMPULAN}

Berdasarkan hasil penelitian maka dapat disimpulkan bahwa hasil dari peneliatian sudah selesai dan hasil sudah dapat di uji coba dan prototipe sudah bisa digunakan. Tetapi masih banyak sekali kesalah sistem karena perancangan dan program belum sempurna. Tetapi dalam proses melalukan penelitian sudah bisa dibilang berhasil karena alat yang diharapkan dapat bekerja dengan semestinya walaupun belum sempurna seperti yang diharapkan. Dan diharapkan dapat dikembangkan oleh peneliti berikutnya.

\section{REFERENSI}

[1] Andrianto, \& Darmawan. (2016). Arduino Belajar Cepat Dan Pemrograman. Bandung: Informatika.

[2] Binanto, I. (2005). Konsep Dasar Program. Jakarta: Pt. Elex Media. Budhi, Y. W. (2015). Panduan Pelaksanaan Laboratorium Instruksional I/I. Bandung: Itb.

[3] S. Samsugi and A. Suwantoro, "Pemanfaatan Peltier dan Heater Sebagai Alat Pengontrol Suhu Air Pada Bak Penetasan Telur Ikan Gurame,” pp. 295-299.

[4] K. Pindrayana, R. Indra Borman, B. Prasetyo, and S. Samsugi, "Prototipe Pemandu Parkir Mobil Dengan Output Suara Manusia Mengunakan Mikrokontroler Arduino Uno," CIRCUIT J. Ilm. Pendidik. Tek. Elektro, vol. 2, no. 2, pp. 71-82, 2018, doi: 10.22373/crc.v2i2.3705.

[5] S. Utama, A. Mulyanto, M. Arif Fauzi, and N. Utami Putri, "Implementasi Sensor Light Dependent Resistor (LDR) Dan LM35 Pada Prototipe Atap Otomatis Berbasis Arduino," CIRCUIT J. Ilm. Pendidik. Tek. Elektro, vol. 2, no. 2, pp. 83-89, 2018, doi: 10.22373/crc.v2i2.3706.

[6] E. Saputro, "Rancang Bangun Pengaman Pintu Otomatis Menggunakan E-KTP Berbasis Mikrokontroler Atmega328," J. Tek. Elektro, vol. 8, no. 1, pp. 1-4, 2016.

[7] H. Supriyono, A. Kurniawan, and A. Rakhmadi, "Perancangan dan pembuatan sistem pintu otomatis menggunakan barcode," KomuniTi, vol. V, no. 1, pp. 17-23, 2013.

[8] Dickson, K. (2015). Teknik Elektronika. Dipetik September 11, 2016, Dari $\quad$ Teknik elektronika.Com: http://teknikelektronika.com

[9] Sejati, P. (2011, Agustus 25). Mengenal Komunikasi I2c (Inter Integrated Circuit). Dipetik September 11, 2016, Dari Purnomosejati's Weblog: https://purnomosejati.wordpress.com/2011/08/25/mengenalkomunikasi-i2cinter-integrated-circuit/

[10] Shankara, U. D. (2009). 8051 Microcontroller: Hardware, Software \& Applications. New Delhi: Tata Mcgraw-Hill Companies. 